\title{
The effect of transformational leadership style and organizational culture on the formation of organizational cynicism in the Agricultural Bank of Tehran
}

\author{
Narges Rabie ${ }^{a}$, Fatemeh Karimi ${ }^{\mathbf{a}, b^{*}}$ and Ali Naimi Sadigh ${ }^{\mathrm{c}}$
}

${ }^{a}$ Department of Management \& Accounting (M.B.A group), Shahrood Science \& Research Branch Islamic Azad University, Shahrood, Iran ${ }^{b}$ Information Technology Research Center, Tarbiat Modares University, Tehran, Iran

'Iranian Research Institute for Information Science and Technology (IRANDOC), Tehran, Iran

CHRONICLE

Article history:

Received January 5, 2016

Received in revised format March

28,2016

Accepted April 2, 2016

Available online

April 2, 2016

Keywords:

Transformational leadership style

Organizational culture

Organizational cynicism

Agricultural bank of Tehran

\section{A B S T R A C T}

\begin{abstract}
The purpose of this study was to evaluate the effect of transformational leadership style and organizational culture on the formation of organizational cynicism in the Agricultural Bank in city of Tehran. The population of this study consisted of 1022 employees of the Agricultural Bank of Tehran. A total of 304 questionnaires were distributed, of which 264 valid questionnaires were collected. These questionnaires were distributed randomly among the male and female employees in Tehran branches of Agricultural Bank. Standard questionnaire of transformational leadership model, standard questionnaire of organizational culture model and organizational cynicism were applied in this study. In this study SPSS19 and Smart PLS software were used to analyze the collected data. Hypothesis testing showed that at first, Transformational leadership style had no significant effect on the formation of organizational cynicism in the Agricultural Bank in Tehran, and organizational culture had a significant negative impact on the formation of organizational cynicism in the Agricultural Bank in the second hypothesis.
\end{abstract}

\section{Introduction}

Transformational leadership is originated to seminal works of Weber et al. (1947) who presents on charm. He mentioned that the authority of a leader could be specified through the followers' perspective (Beck-Tauber, 2012). All the theory on effective leadership behavior, transformational leadership is more specifically relevant to organizational change. Bass and Avolio (1994) offered one of the most effective interpretations of transformational leadership, which consists of four components of transformational leader behavior: "Idealized Influence, Inspirational Motivation, Intellectual Stimulation, and Individualized Consideration". A transformational leader specifies idealized effect in such a way that $\mathrm{s} / \mathrm{he}$ acts as a role model for followers. Inspirational motivation presents behavior through which a transformational leader motivates others by bringing meaning to and challenge to what 
others do. Intellectual stimulation is associated with a transformational leader who encourages followers to be innovative and creative. Finally, individualized consideration means that a transformational leader concentrates on the needs that each follower has in term of his/her own achievement (Penava \& Šehić, 2014).

Transformational leadership can be defined as a leadership motion, which makes changes in individuals and social systems. Under ideal circumstance, it generates valuable and positive change in the followers with the primary objective of developing followers into leaders. Enacted in its authentic form, transformational leadership boosts the motivation, morale and performance of followers according to different mechanisms. These incorporate connecting the follower's sense of identity and self to the mission and the collective identity of the firm; being a role model for followers, which inspires them; challenging followers to take bigger ownership for their work, and learning the strengths as well as weaknesses of followers, so the leader may align followers with tasks that optimize their performance (Penava \& Šehić, 2014).

Burns (1978) is believed to be the first who introduced the concept of transforming leadership in his descriptive study on political leaders, but this term is now applied in organizational psychology as well. According to Burns (1978), "transforming leadership is a process in which leaders and followers help each other to advance to a higher level of morale and motivation”. Burns establishes the difficulty in differentiation between management and leadership and specified that the differences are in characteristics and behaviors. He established two concepts: "transforming leadership" and "transactional leadership". According to Burns, the transforming method builds substantial change in the life of organizations. It redesigns perceptions, and makes changes in employees' expectations. Unlike transactional approach, it is not based on a "give and take" relationship, but on the leader's personality, traits and capability to make a change through example, articulation of an energizing vision and challenging objectives. Transforming leaders are characterized in the sense that they are a moral model of working towards the interest of the organization.

The primary concept of transformational leadership was stated by Burns in his researches about political leaders. According to Burns, transformational leadership is a process in which leaders and followers encourage each other to higher levels of motivation. Transformational leaders help their followers look at old problems via a new perspective (Jandaghi et al., 2008). Transformational leadership is characterized by different patterns of behaviors. First, transformational leadership uses the leaders' charisma to gain stakeholders' trust. Besides, charisma underlines the provision of a common vision and sense of mission necessary for the transformation. The second characteristic is inspiration through which leaders apply symbols to redirect followers' efforts; they express in a simplistic style the fundamental purpose of the transformation process, and clearly communicate the accompanying higher expectations. The third characteristic is associated with intellectual stimulation. Leaders intellectually stimulate staffs by emphasizing rationality and creativity in problem-solving circumstances (Cossin \& Caballero, 2013).

Culture is considered as the arrangement of various attributes, which express an organization and differentiates the firm from other one (Shahzad et al., 2012). Organizational culture conveys shared beliefs, and is the social glue holding an organization together (Tsai, 2011). Organizational culture has been widely implemented the term but is seems to contain a degree of ambiguity. Watson (2006) concentrates that the concept of culture originally extracted from a metaphor of the organization as "something cultivated". During the last few decades, most academics and practitioners who have been studying organizations recommend the concept of culture as the climate and practices that firms develop to the promoted values (Schein, 2004). According to Schein (2004) "the only thing of real importance that leaders do is to create and manage culture; that the unique talent of leaders is their ability to understand and work with culture; and that it is an ultimate act of leadership to destroy culture when it is viewed as dysfunctional culture therefore gives organizations a sense of identity and determines, through the organization's legends, rituals, beliefs, meanings, values, norms and language, 
the way in which 'things are done around here". An organizations' culture enclose what it has been ideal at and what has worked in the past. These practices can often be recognized with no question by long-serving members of a firm. One of the first issues a new employee gains is some of the organization's legends. Legends can stay with a firm and become part of the established way of doing things (O’Donnell \& Boyle, 2008).

While cynicism is an existing in one from birth reflecting generally negative emotions like frustration about human behavior, organizational cynicism is associated with negative behaviors toward one's employing organization composed of cognitive (belief), affective dimensions which are (i) one's belief that the firm lacks integrity, (ii) a negative attitude towards the organization, and (iii) tendencies towards disparaging and exhibiting critical behaviors towards the firm that are consistent with these beliefs (Karadag et al., 2014).

Organizational Cynicism is an employee's having negative attitudes against the organization they work for (Dean et al., 1998). In other words, organizational cynicism is employees' belief that firms do not have ethical principles such as justice, honesty and sincerity are sacrificed for organizational interest (Atwater et al., 2000). Therefore, organizational cynicism is considered when employees believe that their organization does not honesty. This perception can mostly occur where all principal expectations related to justice, ethic and honesty (Dean et al., 1998). It is criticized that organizational cynicism gives a "learned thought" developed as a result of experiences, while it is conceptualized as a futuredirected feature (Johnson \& O'Leary-kelly, 2003). Despite cynicism is explained both as a personality feature and an emotion, it is criticized that organizational cynicism need to be interpreted rather as an employees' reaction to organization's policy and applications than their general features. The reason for employees' negative manners against organization is a type of strategy for dealing with their nonmet requirements. It happens as psychological contract breach of employees in these strategies (Aküzüm, 2014). Organizational cynicism is in conflict with organizational citizenship behaviors in which individuals contribute voluntarily to the accomplishment of organizational objectives. Organizational cynicism has been considered as a multidimensional idea. It includes three dimensions: the cognitive dimension which is associated with beliefs; the emotional dimension which is related to reactions that emerge as a result of negative emotions; and the behavioral dimension which is associated with negative behaviors towards the firm (Konakli et al., 2013). Note that also organizational cynicism, which causes nervous and emotional breakdowns and causes individuals to have psychological/psychosomatic reactions causes similar results on the individual compared with mobbing (Pelit \& Pelit, 2014).

\section{Problem definition}

Today's world is full of complexity, which creates serious challenges for organizations. The role of transformational leadership style, organizational culture and organizational cynicism plays essential in terms of three major factors either positively or negatively on the efficiency and effectiveness of the organization, the development of the organization, enhancing service quality, competitive success, increasing employee motivation, job satisfaction and reducing costs and waste of resources. Organizational cynicism refers to the negative attitude to the organization's employees. The basic belief in organizational cynicism is in the principles of honesty, justice and righteousness leaders' personal interests of the victims and to take actions based on ulterior motives and deceit. If employees are pessimistic, causing many disadvantages for optimal performance of the organization and makes it difficult. In this study, the effects of transformational leadership style and organizational culture on the formation of organizational cynicism are studied and the relationship between test scores transformational leadership style and organizational culture on the formation of organizational cynicism are considered in the Agricultural Bank in Tehran. Therefore the main problem of this study is to examine the effects of transformational leadership style and organizational culture on the formation of organizational cynicism in the Agricultural Bank city of Tehran. 


\subsection{Hypotheses}

- Transformational leadership style and organizational cynicism have significant effects on the formation of the Agricultural Bank city of Tehran.

- Organizational culture and organizational cynicism have significant effects on the formation of the Agricultural Bank city of Tehran.

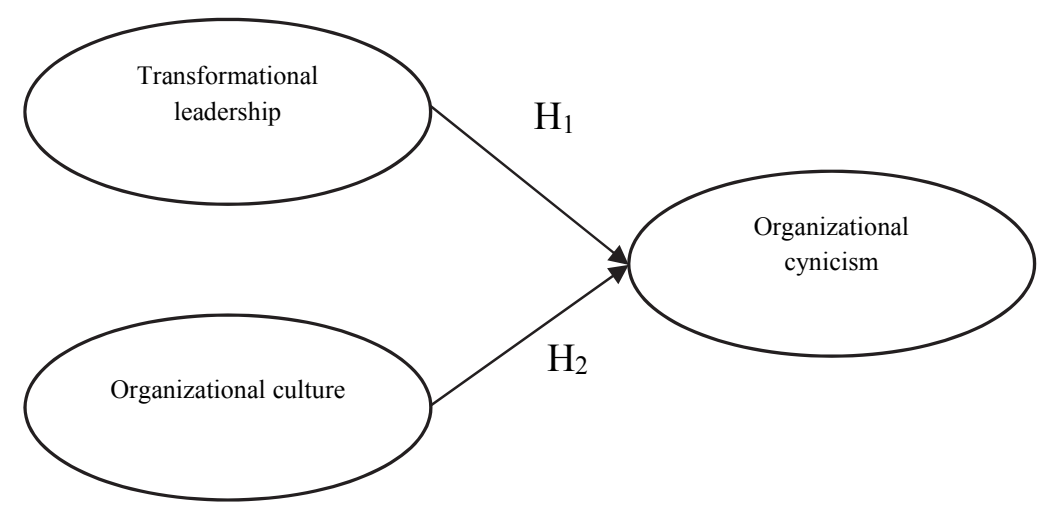

Fig. 1. Conceptual Model

This research is based on applied method and the nature of research is descriptive-survey. The population of the research are all 1022 employees of Agricultural Bank of Tehran. In this study, information was collected based on field study and library. To gather information, transformational leadership, organizational culture and organizational cynicism questionnaire have been used with regard to the dimensions and variables and the subject of the necessary validity and reliability. In this study SPSS19 and Smart PLS software were used to analyze the collected data. In order to categorize and summarize the findings of descriptive statistics (frequency tables and charts for demographics), and to achieve the goals were used of inferential statistics.

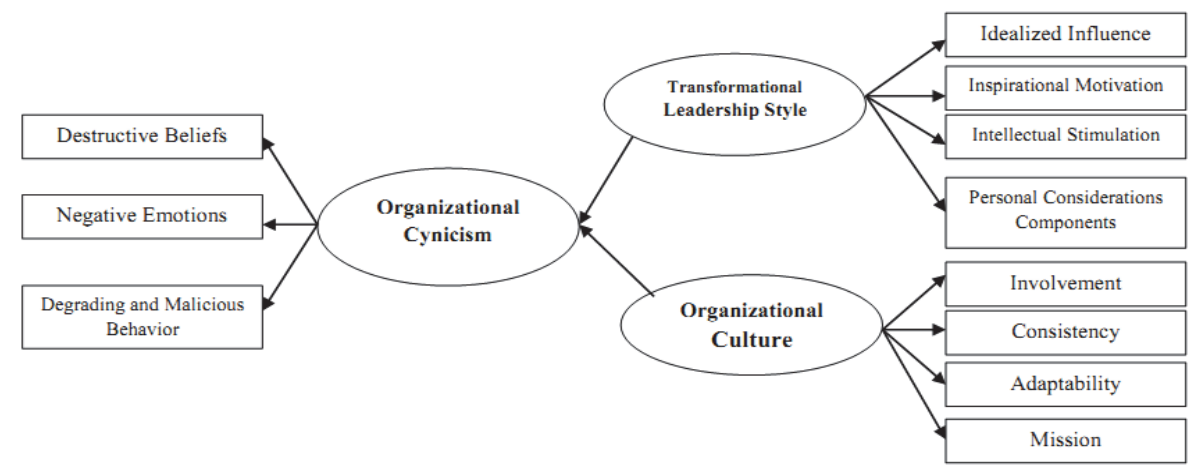

Fig. 2. First and Secod order latent variables of model

After identifying the appropriate variables we must develop a network of relationships among the variables to be created and then we test the hypotheses associated with them. The theoretical framework clarifies the relationship between variables as the theoretical framework forms the basis of the literature review. This means that literature review may identify variables that are important and in fact are the findings of previous studies. The theoretical framework provides a good basis for formulating testable, reasonably and necessary hypotheses (Sekaran, 2003). In this study, we have discussed and examined the impacts of transformational leadership style and organizational culture on the formation of 
organizational cynicism in the Agricultural Bank in Tehran. Thus, according to the literature, the Bass and Avolio model (Bass \& Avolio, 1994) is used to measure the transformational leadership style that includes four idealized influences including inspirational motivation, intellectual stimulation and personal considerations components. To measure organizational culture, Denison model (Denison, 1995) is used that includes four involvements including consistency, adaptability and mission components. To measure organizational cynicism, Dean et al. (1998) model is used, which includes three destructive beliefs, negative emotions and degrading and malicious behavior components (See Fig. 2). The population consisted of Agricultural Bank staff in Tehran that a total of 1022 employees. For sampling, a simple random sampling method is used. Since the population in this study is limited and available, for determining the sample size, Cochran's sample size formula was used and according to this formula, the sample size of 280 is calculated as follows:

$$
n=\frac{N \times Z_{\frac{\alpha}{2}}^{2} \times p \times q}{\varepsilon^{2}(N-1)+Z_{\frac{\alpha}{2}}^{2} \times p \times q}=\frac{1022 \times(1.96)^{2} \times 0.5 \times 0.5}{(0.05)^{2} \times(1022)+(1.96)^{2} \times 0.5 \times 0.5} \cong 280
$$

To gather information related to literature and research literature, library method is used and to collect data to confirm the hypothesis of the study, a questionnaire is used.

1- General inquiries: in the general questions we try to collect sufficient information and demographics on the respondents. This section consists of five questions (age, years of service, gender, marital status and educational level of the respondents).

2- Specific questions: This section consists of 16 questions to assess the transformational leadership 36 questions to assess organizational culture and 12 questions for organizational cynicism. (total 64 questions)

3- 24 questions of 64 questions were eliminated due to their low factor loading coefficients.

The questionnaire is based on five-item Likert scale.

Validity of the questionnaire of this study was based on content validity. The questionnaire was used according to the research hypotheses and then it was confirmed by experts. To estimate the reliability of the questionnaire, Cronbach's alpha was used. According to Table 1, Cronbach alpha coefficient of transformational leadership style questionnaire is 0.865 , organizational culture questionnaire is 0.917 and organizational cynicism questionnaire is 0.829 , respectively. Since Cronbach alpha values obtained for the research components are greater than 0.7 , thus the reliability of the questionnaires are proved.

\section{Table 1}

Cronbach's alpha values

\begin{tabular}{lclc}
\hline Component & Cronbach's alpha & Component & Cronbach's alpha \\
\hline Compatibility & 0.713 & Transformational leadership style & 0.865 \\
Adaptability & 0.831 & Idealized influence & 0.632 \\
Mission & 0.828 & Inspirational motivation & 0.639 \\
Organizational cynicism & 0.829 & Intellectual stimulation & 0.753 \\
Destructive beliefs & 0.749 & Personal considerations & 0.842 \\
Negative emotions & 0.815 & Organizational Culture & 0.917 \\
Degrading and malicious behavior & 0.478 & Engaging in work & 0.754 \\
\hline
\end{tabular}

Fig. 3 shows the results of personal characteristics of the participants in our survey. As we can observe from the results, most participants were married, more than half of them were male employees, and more than two-third of the participants were middle aged people. 


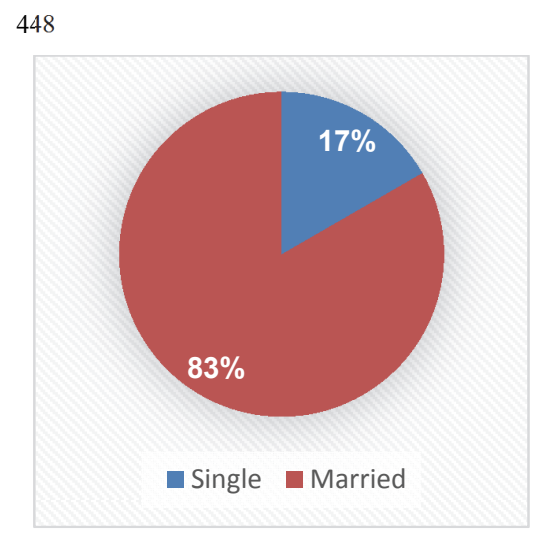

Marital status

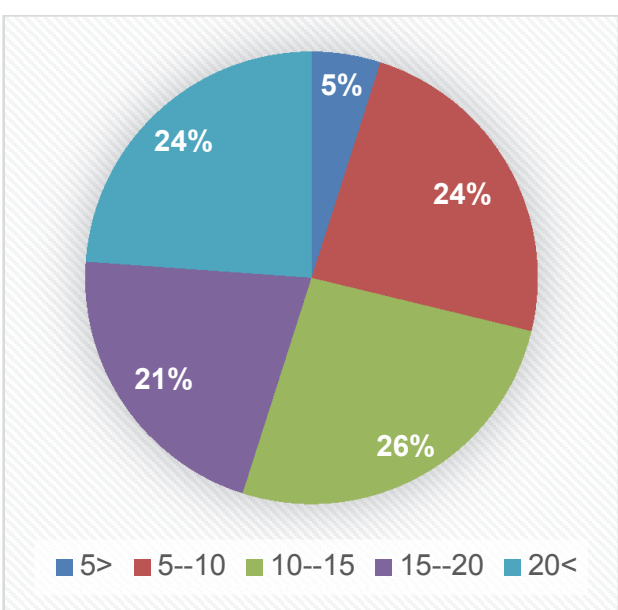

Job experience

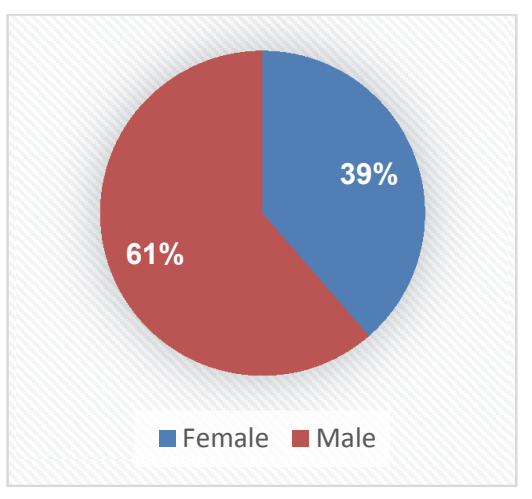

Gender

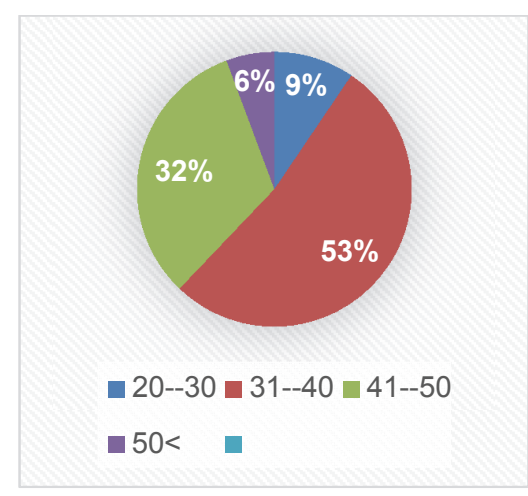

Age

Fig. 3. Personal characteristics of the participants

To determine the normality of data distribution of the collected data, the Kolmogorov-Smirnov test was implied that the results are summarized in Table 2. As we can observe from the data, all components are normally distributed.

\section{Table 2}

Kolmogorov - Smirnov test

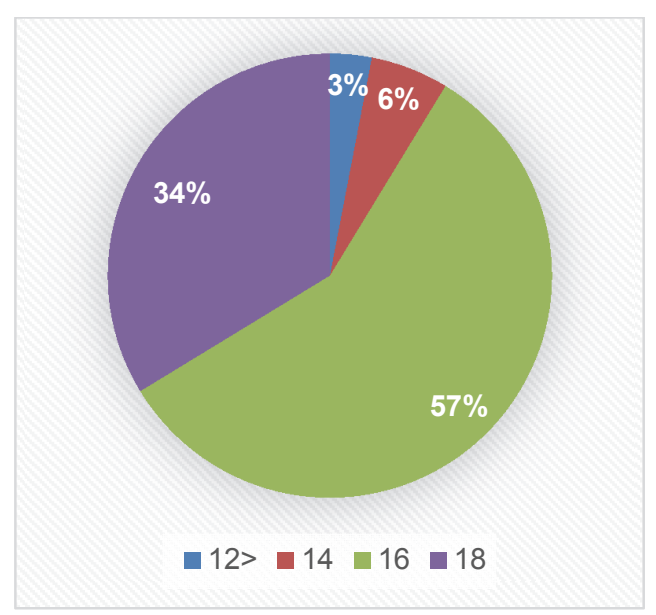

Years of education

\begin{tabular}{cccc}
\hline & $\begin{array}{c}\text { Transformational } \\
\text { leadership style }\end{array}$ & Organizational Culture & $\begin{array}{c}\text { Organizational } \\
\text { cynicism }\end{array}$ \\
\hline Z statistic, Kolmogorov - Smirnov & 0.940 & 0.997 & 0.722 \\
Amount of Sig & 0.340 & 0.273 & 0.675 \\
\hline
\end{tabular}

Table 3 shows the composite reliability coefficients of 11 latent variables and since the coefficients are all above 0.7 , existence of good fit models measure is confirmed.

\section{Table 3}

The composite reliability values

\begin{tabular}{cccc}
\hline component & Composite reliability & component & Composite reliability \\
\hline Compatibility & 0.809 & Transformational leadership style & 0.806 \\
Adaptability & 0.881 & Idealized influence & 0.795 \\
Mission & 0.877 & Inspirational motivation & 0.806 \\
Organizational cynicism & 0.865 & Intellectual stimulation & 0.859 \\
Destructive beliefs & 0.841 & Personal considerations & 0.894 \\
Negative emotions & 0.879 & Organizational Culture & 0.924 \\
Degrading and malicious behavior & 0.758 & Engaging in work & 0.844 \\
\hline
\end{tabular}


Overall composite reliability values show a strong combination to fit their reliability. The second criterion for evaluating the fitness measurement models, convergent validity with questions that studies the correlation of each structure (indicators) of their deals. The average variance extracted (AVE) by PLS software is used for this purpose. Fornell and Larcker (1981) introduced appropriate value for the average variance extracted up to 0.5 . First, the convergent validity was investigated for the first-order latent variables. As the results show this index is more than 0.5 in the first-order latent variables idealized influence, inspirational motivation, intellectual stimulation, personal considerations, involvement, consistency, adaptability, mission, beliefs, destructive, negative emotions and behaviors degrading and malicious that shows the goodness of fit the model.

\section{Table 4}

The average variance extracted values

\begin{tabular}{cccc}
\hline Component & AVE & Component & AVE \\
\hline Compatibility & 0.635 & Transformational leadership style & 0.367 \\
Adaptability & 0.598 & Idealized influence & 0.724 \\
Mission & 0.540 & Inspirational motivation & 0.581 \\
Organizational cynicism & 0.363 & Intellectual stimulation & 0.670 \\
Destructive beliefs & 0.570 & Personal considerations & 0.679 \\
Negative emotions & 0.648 & Organizational Culture & 0.272 \\
Degrading and malicious behavior & 0.657 & Engaging in work & 0.576 \\
\hline
\end{tabular}

After studying the first order latent variables validity, second order latent variables that include transformational leadership style, organizational culture and organizational cynicism were analyzed. Here we must manually calculate the average variance extracted values of the variables transformational leadership style, organizational culture and organizational cynicism. The AVE of a second order latent variable is equal to the square of the mean values of the factor loadings as follows.

$A V E($ Transformational leadership style $)=\frac{(0.725)^{2}+(0.581)^{2}+(0.670)^{2}+(0.679)^{2}}{4}=0.443$

$A V E($ Organizational Culture $)=\frac{(0.576)^{2}+(0.635)^{2}+(0.598)^{2}+(0.540)^{2}}{4}=0.346$

$A V E($ Organizational cynicism $)=\frac{(0.570)^{2}+(0.648)^{2}+(0.657)^{2}}{3}=0.392$

Due to the higher of the average variance extracted of first order and second order latent variables, we have confirmed concurrent validity and appropriateness of fitting indexes of measurement models. The third criterion for evaluating the goodness of fit of measurement models is divergent validity that covers two subjects: A) Compare the correlation between the indicators of a factor, on the contrary the index correlation with other factors. B) Comparison of a structural correlation with its indexes on the contrary the correlation between a factor and other factors.

The following table is the same Fornell and Larcker (1981) matrix with the difference that the square root of the average variance extracted of variables is entered in the main diagonal and another point is that just first order latent variables are entered in this matrix.

Based on the information given in Table 5, the square root of the average variance extracted of all first order latent variables are greater than the correlation between them, so this shows the divergent validity and goodness of fit of the measurement model. 
Table 5

Validity Msearment Matrix , Fornell \& Larcker method

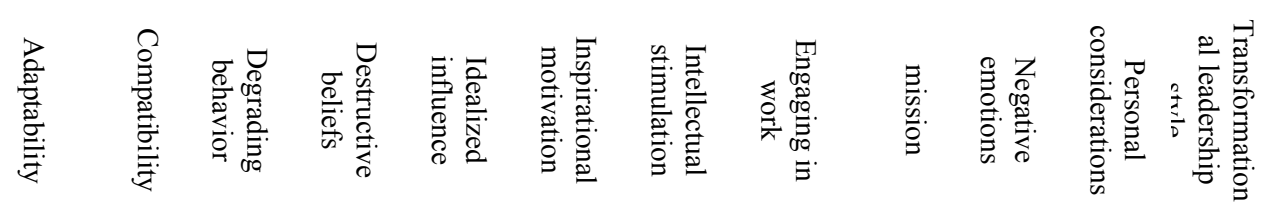

\begin{tabular}{|c|c|c|c|c|c|c|c|c|c|c|c|c|}
\hline Adaptability & 0.773 & & & & & & & & & & & \\
\hline Compatibility & 0.730 & 0.797 & & & & & & & & & & \\
\hline $\begin{array}{l}\text { Degrading } \\
\text { behavior }\end{array}$ & 0.279 & 0.209 & 0.810 & & & & & & & & & \\
\hline Destructive beliefs & 0.406 & 0.294 & 0.405 & 0.755 & & & & & & & & \\
\hline Idealized influence & 0.033 & -0.014 & -0.210 & -0.011 & 0.851 & & & & & & & \\
\hline $\begin{array}{c}\text { Inspirational } \\
\text { motivation }\end{array}$ & 0.139 & 0.074 & -0.233 & -0.108 & 0.576 & 0.762 & & & & & & \\
\hline $\begin{array}{l}\text { Intellectual } \\
\text { stimulation }\end{array}$ & 0.074 & 0.035 & -0.154 & -0.061 & 0.515 & 0.596 & 0.818 & & & & & \\
\hline Engaging in work & 0.134 & 0.211 & -0.026 & -0.116 & 0.305 & 0.373 & 0.370 & 0.759 & & & & \\
\hline mission & 0.682 & 0.586 & 0.123 & 0.315 & 0.227 & 0.209 & 0.133 & 0.231 & 0.734 & & & \\
\hline Negative emotions & 0.335 & 0.244 & 0.605 & 0.481 & -0.197 & -0.227 & -0.184 & -0.176 & 0.102 & 0.805 & & \\
\hline $\begin{array}{c}\text { Personal } \\
\text { considerations }\end{array}$ & 0.057 & 0.094 & -0.134 & -0.062 & 0.447 & 0.486 & 0.620 & 0.494 & 0.121 & -0.193 & 0.824 & \\
\hline $\begin{array}{l}\text { Transformational } \\
\text { leadership style }\end{array}$ & 0.109 & 0.075 & -0.209 & -0.074 & 0.727 & 0.799 & 0.854 & 0.488 & 0.213 & -0.241 & 0.830 & 0.606 \\
\hline
\end{tabular}

\section{The structural model and Hypotheses test}

\subsection{Measurement of factor loadings}

The criteria for suitability factor loadings coefficients is 0.66 .24 questions out of 64 questions have a load factor less than 0.66 . These questions must be removed for the rest of analysis. After removing these questions, all of the questions in the questionnaire have maintained load factors greater than 0.66, which indicates the suitability of this measure.

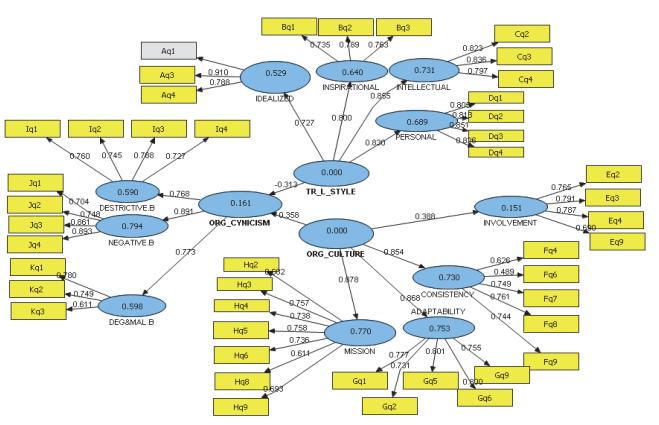

Fig. 4. Path Analysis for general structural equation modeling research

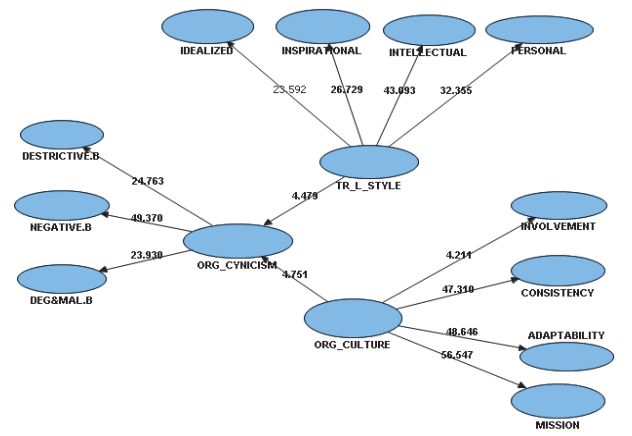

Fig. 5. Path Analysis of Structural Equation Model for the overall study, after removing the questions ( $\mathrm{t}$ values) 
Among the routes in the model, the coefficient of the organizational culture to organizational cynicism is greater than 1.96 that indicates significance of this route.

\section{Table 6}

Rout coefficients

\begin{tabular}{lc}
\hline Route & Coefficient \\
\hline The transformational leadership style route to organizational cynicism & 4.479 \\
The organizational culture route to organizational cynicism & 4.751 \\
\hline
\end{tabular}

$\mathrm{R}^{2}$ is a criterion that demonstrates the impact of exogenous variables on the endogenous variables. Table 7 demonstrates the results of $\mathrm{R}^{2}$.

Table 7

\begin{tabular}{cccccc}
$\mathrm{R}^{2}$ and Chi-Square values & \multicolumn{7}{l}{} \\
\hline Component & $\mathrm{R}^{2}$ & Chi-Square & Component & $\mathrm{R}^{2}$ & Chi-Square \\
\hline Adaptability & 0.765 & 0.382 & Idealized influence & 0.528 & 0.455 \\
mission & 0.770 & 0.453 & Inspirational motivation & 0.639 & 0.564 \\
organizational cynicism & 0.168 & 0.052 & Intellectual stimulation & 0.730 & 0.567 \\
Destructive beliefs & 0.596 & 0.301 & Personal considerations & 0.688 & 0.456 \\
Negative emotions & 0.795 & 0.630 & Engaging in work & 0.139 & 0.310 \\
Degrading and malicious behavior & 0.570 & 0.350 & Compatibility & 0.639 & 0.352
\end{tabular}

- $\mathrm{R}^{2}$ values of the variables intellectual stimulation, adaptability, personal considerations, mission and negative emotions are more than 0.67 , which indicates the strong influence of these variables on endogenous variables of the model.

- $\mathrm{R}^{2}$ values of the variables destructive beliefs, degrading and malicious behavior, inspirational motivation and idealized influence are more than 0.33 , which indicates the average impact of these variables on endogenous variables of the model.

- $\mathrm{R}^{2}$ value of organizational cynicism and engaging in work are less than 0.33 that reflecting a weaker influence of these variables on endogenous variables of the model.

Based on the information of Table 7 we can conclude that

- The Chi-Square values of idealized influence, inspirational motivation, intellectual stimulation, personal considerations, compatibility, adaptability, mission, beliefs, destructive, negative emotions and degrading and malicious behavior are more than 0.35 , which indicates strong prediction power of endogenous variables of the model.

- The Chi-Square values of Engaging in work and destructive beliefs are more than 0.15 , which indicates the average prediction power of endogenous variables of the model's.

- The Chi-Square value of organizational cynicism is less than 0.15 , which indicates a poorer prediction power of endogenous variables in the model.

In this survey, three of the model quality tests include :CV Com, CV Red and GOF. The Redundancy measure is obtained by multiplying the values of communal variables in their respective values and indicates some variability indices is an endogenous variable that affected by one or more exogenous variables. Redundancy of the endogenous variables of model is calculated in Table 8. 


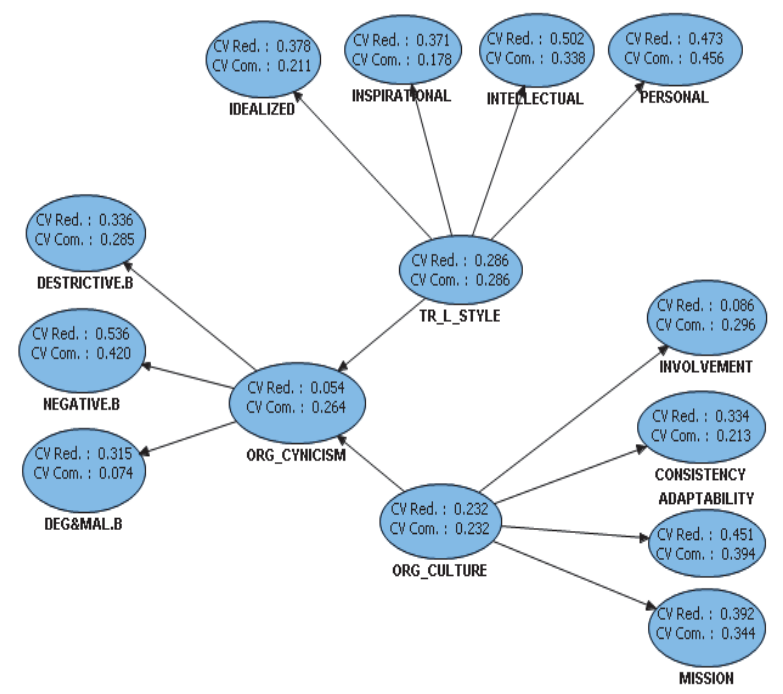

Fig. 3. The results of CV Red \& CV Com values

Table 8

Overview of coefficients

\begin{tabular}{|c|c|c|c|c|c|c|}
\hline & AVE & Composite Reliability & R Square & Cronbachs Alpha & Communality & Redundancy \\
\hline ADAPTABILITY & 0.598396 & 0.881527 & 0.765243 & 0.831713 & 0.598396 & 0.456010 \\
\hline CONSISTENCY & 0.635447 & 0.839435 & 0.639219 & 0.713349 & 0.635447 & 0.405270 \\
\hline DEG\&MAL.B & 0.657002 & 0.792914 & 0.570916 & 0.478668 & 0.657002 & 0.374761 \\
\hline DESTRICTIVE.B & 0.570823 & 0.841661 & 0.596806 & 0.749444 & 0.570823 & 0.337762 \\
\hline IDEALIZED & 0.724605 & 0.839622 & 0.528957 & 0.632000 & 0.724605 & 0.372103 \\
\hline INSPIRATIONAL & 0.581293 & 0.806257 & 0.639920 & 0.639287 & 0.581293 & 0.371883 \\
\hline INTELLECTUAL & 0.670308 & 0.859095 & 0.730614 & 0.753871 & 0.670308 & 0.489429 \\
\hline INVOLVEMENT & 0.576385 & 0.844396 & 0.139949 & 0.754270 & 0.576385 & 0.078922 \\
\hline MISSION & 0.540106 & 0.875387 & 0.770224 & 0.828885 & 0.540106 & 0.414729 \\
\hline NEGATIVE.B & 0.648549 & 0.879704 & 0.795361 & 0.815938 & 0.648549 & 0.515383 \\
\hline ORG_CULTURE & 0.272650 & 0.924169 & & 0.917847 & 0.272650 & \\
\hline ORG_CYNICISM & 0.363273 & 0.864789 & 0.168872 & 0.829182 & 0.363273 & 0.024948 \\
\hline PERSONAL & 0.679077 & 0.894294 & 0.688908 & 0.842451 & 0.679077 & 0.465038 \\
\hline TR_L_STYLE & 0.367342 & 0.889998 & & 0.865588 & 0.367342 & \\
\hline
\end{tabular}

$$
\begin{gathered}
\overline{\operatorname{Red}}=\frac{\operatorname{Red}_{\mathrm{A} 1}+\operatorname{Red}_{\mathrm{A} 2}+\operatorname{Red}_{\mathrm{A} 3}+\operatorname{Red}_{\mathrm{A} 4}+\operatorname{Red}_{\mathrm{B} 1}+\operatorname{Red}_{\mathrm{B} 2}+\operatorname{Red}_{\mathrm{B} 3}+\operatorname{Red}_{\mathrm{B} 4}+\operatorname{Red}_{\mathrm{C}}+\operatorname{Red}_{\mathrm{C} 1}+\operatorname{Red}_{\mathrm{C} 2}+\operatorname{Red}_{\mathrm{C} 3}}{12}= \\
\frac{0.456+0.405+0.374+0.337+0.372+0.371+0.489+0.078+0.414+0.515+0.024+0.465}{12}=0.358
\end{gathered}
$$

The higher the value (Red), the more fitness of structural model.

To review the overall model that controls both measurement and structural models, GOF criterion is calculated as follows:

$$
\text { GoF }=\sqrt{\overline{\text { Communalities }} \times \overline{R^{2}}}
$$

$\overline{\text { Communalities }}$ value comes out of average of shared values of first order latent variables idealized influence, inspirational motivation, intellectual stimulation, personal considerations, involvement, consistency, adaptability, mission, beliefs, destructive, negative emotions and degrading and malicious behavior. As a result, average of shared values is: 0.563 
Table 9

Average of shared values of first order latent variables

\begin{tabular}{cccc}
\hline Component & $\begin{array}{c}\text { average of shared values of } \\
\text { first order latent variables }\end{array}$ & Component & $\begin{array}{c}\text { average of shared values of first } \\
\text { order latent variables }\end{array}$ \\
\hline Adaptability & 0.671 & Idealized influence & 0.563 \\
mission & 0.625 & Inspirational motivation & 0.612 \\
Destructive beliefs & 0.580 & Intellectual stimulation & 0.696 \\
Negative emotions & 0.717 & Personal considerations & 0.675 \\
Degrading and malicious behavior & 0.554 & Engaging in work & 0.294 \\
& & Compatibility & 0.582 \\
\hline
\end{tabular}

To calculate $\left(\mathrm{R}^{2}\right)$ we must calculate $\mathrm{R}^{2}$ values of both first and second order of all endogenous latent variables in the model and the average value. $\mathrm{R}^{2}$ values for the variables are listed in Table 9 . So the average of these values is 0.582 .

$$
\text { GoF }=\sqrt{\overline{\text { Communalities }} \times \overline{R^{2}}}=\sqrt{0.563 \times 0.582}=0.574
$$

According to the three values of $0.01,0.25$, and 0.36 as values of weak, medium and strong for GOF, which yields .574 for GOF, showing a strong overall quality of the model.

\section{Conclusion and future research}

Bass and Avolio (1994) suggest that the survival of the organization depends on effective leadership. This occurs especially when the organization is facing a period of change. Since transformational leaders are always worried about the modernization of the organization, they will be followed by development of organizational culture in terms of creativity, problem solving, risk-taking and experimentation are favorable. On the other hand, given the important role of banks in the economy, it can be said that it is important to consider different factors affecting the performance of employees working in the bank. Among the important factors are optimistic and pessimistic attitude to the bank's employees. Given that the Agricultural Bank is one of the most important organizations serving the service and the various strata of the population, it has particular importance in strengthening the transformational leadership style and organizational culture and improving view of customers and the community because employees with a strong spirit in a quiet and full of motivation workplace are optimistic to their work environment, will have better performance. Conversely, employees who work with the pessimism of the mind, certainly not efficient and it will have undesirable consequences for client. Therefore, having employees who have a positive attitude towards the work environment in Agricultural Bank, will be most effective in delivering services, it also requires transformational leadership and a strong corporate culture is related to the Agricultural Bank which requires related transformational leadership and a strong corporate culture.

\section{References}

Aküzüm, C. (2014). The Effect of Organizational Justice and Organizational Cynicism on the Organizational Commitment: An Application in Primary Education Institutions. Mevlana International Journal of Education (MIJE),4(3), 48-68.

Atwater, L. E., Waldman, D. A., Atwater, D., \& Cartier, P. (2000) An upward feedback field experiment. Supervisors'cynicism, follow-up and commitment to subordinates. Personnel Psychology, 53(2), 275-297.

Bass, B. M., \& Avolio, B. J. (1994). Improving Organizational Effectiveness Through Transformational Leadership. Sage Publications 
Beck-Tauber, D. (2013). Transformational Leadership:Exploring its Functionality. DISSERTATION of the University of St. Gallen,School of Management:Transformational Leadership:Exploring its Functionality. Munich, Munich, Germany: University of St. Gallen,School of Management.

Burns, J. M. (1978). Leadership Harper \& Row. New York.

Cossin, D., \& Caballero, J. (2013). Transformational Leadership, background literature review. Working Paper, IMD Business School.

Dean, J. W., Brandes, P., \& Dharwadkar, R. (1998). Organizational cynicism.Academy of Management review, 23(2), 341-352.

Denison, D. R. (1990). Corporate culture and organizational effectiveness. John Wiley \& Sons.

Fornell, C., \& Larcker, D. F. (1981). Structural equation models with unobservable variables and measurement error: Algebra and statistics.Journal of Marketing Research, 18(3), 382-388.

Henseler, J., Ringle, C. M., \& Sinkovics, R. R. (2009). The use of partial least squares path modeling in international marketing. Advances in International Marketing, 20(1), 277-319.

Jandaghi, G., Matin, H. Z., \& Farjami, A. (2008). Comparing transformational leadership in successful and unsuccessful companies. World Academy of Science, Engineering and Technology, International Journal of Social, Behavioral, Educational, Economic and Management Engineering, 2(5), 621-626.

Johnson, J. L., \& O'Leary-Kelly, A. M. (2003). The effects of psychological contract breach and organizational cynicism: Not all social exchange violations are created equal. Journal of Organizational Behavior, 24(5), 627-647.

Karadag, E., Kilicoglu, G., \& Yilmaz, D. (2014). Organizational Cynicism, School Culture, and Academic Achievement: The Study of Structural Equation Modeling. Educational Sciences: Theory \& Practice, 14(1), 102-113.

Konakli, T., Özyilmaz, G., \& Çörtük, S. (2013). Impact of school managers' altruist behaviors upon organizational cynicism: The case of Kocaeli, Turkey.Educational Research and Reviews, 8(24), 2317.

O’Donnell, O., \& Boyle, R. (2008). Understanding and Managing Organisational Culture. In O. O’Donnell, \& R. Boyle, Understanding and Managing Organisational Culture (pp. 4-5). Dublin: Institute of Public Administration http://www.ipa.ie/.

Pelit, E., \& Pelit, N. (2014). The effects of mobbing on organizational cynicism: A study on hotels in Turkey. International Journal of Human Resource Studies, 4(1), 34.

Penava, S., \& Šehić, D. (2014). The relevance of transformational leadership in shaping employee attitudes towards organizational change. Economic Annals, 59(200), 131-162.

Schein, E. (2004). Organizational Culture and Leadership, Third Edition. San Francisco: Jossey-Bass. Sekaran, U. (2003). Research methods for business : a skill-building approach. New York: Wiley.

Shahzad, F., Luqman, R. A., Khan, A. R., \& Shabbir, L. (2012). Impact of organizational culture on organizational performance: an overview.Interdisciplinary journal of contemporary research in business, 3(9), 975.

Tsai, Y. (2011). Relationship between organizational culture, leadership behavior and job satisfaction. BMC health services research, 11(1), 1472-6963.

Watson, T. (2006). Organising and Managing Work. london: UK: Pearson.

Weber, M., Henderson, A. M., \& Parsons, T. (1947). The theory of social and economic organization: being Part I of Wirtschaft und Gesellschaft: W. Hodge.

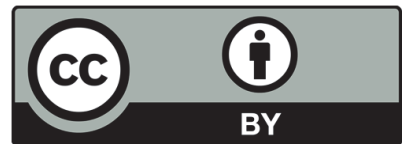

(C) 2016 by the authors; licensee Growing Science, Canada. This is an open access article distributed under the terms and conditions of the Creative Commons Attribution (CC-BY) license (http://creativecommons.org/licenses/by/4.0/). 